\title{
EFEITO DE MOMORDICA CHARANTIA L. EM CAMUNDONGOS INFECTADOS POR PLASMODIUM BERGHEI
}

\author{
Helene Mariko Ueno, Julio T. Doyama, Carlos Roberto \\ Padovani e Ednir Salata
}

\begin{abstract}
A Organização Mundial de Saúde (OMS) citou a malāria como um dos principais problemas de saúde no Brasil e no terceiro mundo, onde $80 \%$ da populaça rocorre à medicina tradicional (popular) para sanar tários problemas de assistência médica primária. No que se refere à malāria, seu tratamento e controle têm sido dificultados devido às cepas resistentes às drogas comumente utilizadas. Isso torna urgente a busca de novas drogas antimaláricas. Sabe-se que a população utiliza-se de diferentes plantas para o tratamento e cura de vários males, inclusive a malāria. Neste trabalbo nos propusemos reataliar o efeito de Momordica charantia L. (Cucurbitaceae) sobre camundongos infectados por Plasmodium berghei. A planta foi testada sob a forma de extratos aquoso e etanólico, na dose de $1000 \mathrm{mg}$ por $\mathrm{kg}$ de peso corpóreo do camundongo, ministrado por zia oral. por cinco dias consecutivos da infeç̧ão (2ao $\left.6^{\circ}\right)$. O efeito foi analiado em função da parasitemia e da sobrevida dos animais. Embora a populaçâo indique e utilize essa planta na malâria bumana. nos ensaios deste trabalbo, nas condiçôes do experimento, os extratos de $M$. charantia não apresentaram atividade satisfatória contra o $P$. berghei
\end{abstract}

Palavras-chates: Momordica. Plasmodium berghei. Antimalárico.

Por muitos anos, o quinino foi a droga de escolha para o tratamento da malária ${ }^{27}$. Porém, na década de 30 , este alcalóide encontrado na casca de Cincbona sp L. (Rubiaceae) ${ }^{20}$, foi sendo substituido por drogas sintéticas, como 8-aminoquinolinas (primaquina), 4 aminoquinolinas (cloroquina, amodiaquina) e inibidores da síntese do ácido fólico (pirimetamina, proguanil). Por volta dos anos 50 , acreditava-se que a malária poderia ser erradicada em todo o mundo ${ }^{25} 26$, sendo que no Brasil chegou a ser controlada por volta da década de $50^{17}$.

Entretanto, nos últimos anos, a endemicidade da malária tem aumentado acentuadamente ${ }^{33}$, devido às migrações populacionais incontroláveis ${ }^{19}$, à pequena vigilância epidemiológica, ao aparecimento de mosquitos resistentes aos inseticidas, à falta de recursos para o controle do vetor e ao surgimento de cepas resistentes

\footnotetext{
Departamento de Parasitologia, de Químicà, de Bioestatística e de Parasitologia do Instituto de Biociências da Universidade Estadual Paulista/Campus de Botucatu, Botucatu, SP.

Endereço para correspondência: Dr. Ednir Salata. Departamento de Parasitologia, Pç. Rubião Junior, 18168-000 Botucatu, SP, Brasil. Fax: (014) 821-3744.

Recebido para publicação em 22/09/95.
}

de Plasmodium falciparumi 112830 e do $P$. viva $x^{13} 31$ aos quimioterápicos usuais. Além da questão da resistência do parasito às drogas, Carvalho e cols ${ }^{\top}$ chamam a atenção às reações adversas, como a neutropenia e agranulocitose severas, decorrentes da quimioprofilaxia antimalárica por amodiaquina e pirimetamina associada ao dapsone.

A busca de novos medicamentos pode ser feita através da síntese de novos compostos, modificação molecular de substâncias com atividade farmacológica descrita e a partir de produtos naturais, especialmente de espécies vegetais. Considerando-se compostos sintéticos, diversas drogas, contra cepas resistentes à cloroquina e multi-resistentes vêm sendo estudadas. A deferoxamina, um quelante de ferro, foi testada sem o sucesso desejado ${ }^{6}$. O uso de sulfa de meia vida curta associada ao proguanil foi indicado, já que as de meia vida longa podem trazer reações adversas sérias 5 . Também o uso de antibióticos inibidores da síntese protéica, como a eritromicina e azitromicina, foi indicado ${ }^{14}$. Novas drogas, como o fenantreno-metanol, halofantrine $e$ hidroclorida estão sendo desenvolvidas com o intuito de controlar o fenômeno da resistência do Plasmodium ${ }^{12}$. 
Ueno HM, Doyama JT, Padotani CR, Salata E. Efeito de Momordica charantia L. em camundongos infectados por Plasmodium berghei. Revista da Sociedade Brasileira de Medicina Tropical 29:455-460, set-out, 1996.

Do ponto de vista de compostos de origem natural, a artemisinina foi isolada a partir de Artemisia annua. A artemisinina e vários de seus derivados possuem atividade antimalárica, sendo a droga de escolha no tratamento da malária cerebral e em pacientes que não respondem ao quinino (cloroquinaresistente $)^{4102122}$. Janse e cols ${ }^{15}$, estudaram a atividade da artemisinina e seus derivados contra $P$. berghei in vivo e in vitro.

Além da Artemisia annua, inúmeras espécies vegetais têm sido estudadas quanto suas atividades antimaláricas ${ }^{123918}$ inclusive Momordica charantia cuja diminuição discreta de parasitemia foi relatada por Ornellas e cols ${ }^{24}$ e Neves e cols ${ }^{23}$. No entanto, um estudo com folhas e caules frescos, desta espécie, torna-se importante na reavaliação da diminuição da parasitemia em camundongos infectados por $P$. berghei.

\section{MATERIAL E MÉTODOS}

A atividade antimalárica de extratos de Momordica charantia foi avaliada pelo tratamento de camundongos infectados com Plasmodium berghei.

Após a identificação da planta pelo Dr. Luiz Roberto Hernandes Bicudo, do Departamento de Botânica do Instituto de Biociências da UNESP-Campus de Botucatu, folhas e caules frescos foram coletados e levados ao laboratório para o preparo de extratos aquoso e etanólico.

Extrato aquoso. Cerca de $200 \mathrm{~g}$ da planta, já lavada, foram triturados em água e, após a remoção dos resíduos sólidos, o material foi centrifugado e o sobrenadante filtrado a vácuo. $\mathrm{O}$ extrato foi concentrado até $105 \mathrm{mg} / \mathrm{ml} \mathrm{em}$ estufa a $60^{\circ} \mathrm{C}$. A determinação dessa concentração foi feita a partir do peso seco de aliquotas de $0,2 \mathrm{ml}$ em estufa a $80^{\circ} \mathrm{C}$.

Extrato etanólico. Foi obtido do mesmo modo anterior, utilizando-se como solvente o etanol. A evaporação do solvente foi realizada em evaporador rotativo (rota-vapor), seguido de liofilização. O produto liofilizado foi dissolvido em água para se obter $105 \mathrm{mg} / \mathrm{ml} \mathrm{de}$ extrato.

Infecção e testes antimaláricos em camundongos. Camundongos swiss de 55 dias de idade, pesando em média $34 \mathrm{~g}$, machos, foram inoculados com $1 \times 10^{6}$ hemácias parasitadas por $P$. berghei, por via intraperitonial.
Os camundongos foram separados em grupos de 10 animais e mantidos em caixa de cơntenção, com água e ração ad libitum, foto periodo de 12 horas, no Laboratório de Experimentação Animal do Departamento de Parasitologia.

Grupo I. Avaliação da parasitemia - grupo contrôle: 10 camundongos infectados e "tratados" com solução fisiológica.

Grupo II. Avaliação da sobrevida - grupo contrôle: 10 camundongos infectados $\mathrm{e}$ "tratados" com solução fisiológica.

Grupo III. Avaliaçâo da parasitemia - grupo tratado: 10 camundongos infectados e tratados com extrato aquoso da planta.

Grupo IV. Avaliação da sobrevida - grupo tratado: 10 camundongos infectados e tratados com extrato aquoso da planta.

Grupo $V$. Avaliação da toxicidade do extrato: 10 camundongos que receberam por via intraperitoneal apenas solução fisiológica e extrato aquoso da planta por via oral.

O tratamento foi ministrado por via oral, nos dias 2, 3, 4, 5, e 6 após o inóculo infectante na dose de $1000 \mathrm{mg}$ de extrato por $\mathrm{kg}$ de peso corpóreo do camundongo.

Grupos semelhantes foram constituídos para testar atividade antimalárica em extrato etanólico.

Parâmetros de avaliação de atividade antimalârica. Utilizamos dois parâmetros para avaliar possível atividade antimalárica nos extratos da planta:

Parasitemia dos animais infectados. Foram feitos esfregaços de sangue, coletado da cauda dos animais dos grupos I e III, no $9^{\circ}$ dia após o inóculo infectante que, após fixados em metanol e corados por Giemsa, foram observados ao microscópio óptico, objetiva de imersão. Em cada um dos esfregaços foram feitas duas contagens do número de hemácias parasitadas por 1000 examinadas.

Avaliação da sobrevida dos camundongos. Diariamente, durante 30 dias, os animais dos grupos II, IV e $\mathrm{V}$ foram observados para registro da sobrevida.

\section{RESULTADOS}

Os valores individuais da contagem do número de hemácias parasitadas $/ 1000$ examinadas, no $9^{\circ}$ dia após o inóculo infectante, revelaram grande variabilidade. 
Ueno HM, Doyama JT, Padovani CR, Salata E. Efeito de Momordica charantia L. em camundongos infectados por Plasmodium berghei. Revista da Sociedade Brasileira de Medicina Tropical 29:455-460, set-out, 1996.

Expressamos na Tabela 1, as medianas e as semi-amplitudes de variação das parasitemias, bem como o tempo de sobrevida em dias, dos vários grupos de camundongos.

\begin{tabular}{|c|c|c|c|}
\hline Extrato & Grupo & Parasitemia & $\begin{array}{l}\text { Tempo de vida } \\
\text { (em dias) }\end{array}$ \\
\hline \multirow{5}{*}{ Aquoso } & I & $47,50 \pm 39,00$ & - \\
\hline & II & - & $15,50 \pm 7,50$ \\
\hline & III & $46,50 \pm 67,25$ & - \\
\hline & IV & - & $16,00 \pm 7.50$ \\
\hline & V & - & $30,00 \pm 0,00$ \\
\hline \multirow{5}{*}{ Etanólico } & $I$ & $90,25 \pm 66,00$ & - \\
\hline & II & - & $14,50 \pm 6,00$ \\
\hline & III & $77,00 \pm 82,50$ & - \\
\hline & iv & - & $23,00 \pm 9,50$ \\
\hline & $\mathrm{v}$ & - & $15,00 \pm 14,00$ \\
\hline
\end{tabular}

Na Tabela 2, pode-se observar a sobrevida, por período de 5 dias dos camundongos dos diferentes grupos experimentais.

\begin{tabular}{|c|c|c|c|c|c|c|c|}
\hline \multirow{2}{*}{\multicolumn{2}{|c|}{ Extrato Grupo }} & \multicolumn{6}{|c|}{ Período de sobrevida (dias) } \\
\hline & & 025 & 6 a 10 & 11 a 15 & 16 a 20 & 21 a 25 & $\overline{26} \overline{\text { a } 30}$ \\
\hline \multirow{3}{*}{ Aquoso } & II & 9 & 8 & 5 & 0 & 0 & $\overline{0}$ \\
\hline & IV & 10 & 8 & 6 & 1 & 0 & 0 \\
\hline & $\mathrm{V}$ & 10 & 10 & 10 & 10 & 10 & 10 \\
\hline \multirow{3}{*}{ Etanólico } & II & 10 & 9 & 4 & 0 & 0 & 0 \\
\hline & IV & 10 & 10 & 6 & 5 & 5 & 5 \\
\hline & V & 9 & 9 & 4 & 4 & 3 & 3 \\
\hline
\end{tabular}

Como se pode observar na Tabela 3, não houve diferença significativa da parasitemia entre os grupos I e III, nem quando utilizamos extrato aquoso nem com o uso do etanólico.

Tabela 3 - Postos médios da parasitemia de camundongos infectados por P. berghei e tratados com salina ou com extrato aquoso ou etanólico de $\mathrm{M}$. charantia, com respectivo resultado do teste estatistico de Mann-Whitney'.

\begin{tabular}{|c|c|c|c|c|}
\hline \multirow[t]{2}{*}{ Extrato } & \multicolumn{2}{|c|}{$\begin{array}{c}\text { Postos médios } \\
\text { do grupo }\end{array}$} & \multirow[t]{2}{*}{$\begin{array}{l}\text { Resultado do teste } \\
\text { estatístico ( } \mathrm{p} \text {-value) }\end{array}$} & \multirow[t]{2}{*}{ Conclusão } \\
\hline & $I$ & III & & \\
\hline Aquoso & 10,4 & 10,6 & $U=49(p>0,05)$ & $G I=G I I I$ \\
\hline Etanólico & 11,1 & 9,9 & $\mathrm{U}=44(\mathrm{p}>0,05)$ & $G I=G I I I$ \\
\hline
\end{tabular}

A análise estatística apresentada na Tabela 4, revela que os grupos de camundongos infectados e tratados, seja com extrato aquoso seja com etanólico, tiveram sobrevida igual aos grupos de camundongos infectados e "tratados" apenas com solução fisiológica. Por outro lado, os animais que receberam somente extrato, tanto aquoso quanto etanólico (Grupos V), não manifestaram, no período de observação, reações adversas ou indicativas de intoxicação perceptíveis, como se pode observar pela sobrevida expressa na Tabela 2 e no teste estatístico apresentado na Tabela 4 .

\begin{tabular}{|c|c|c|c|c|c|}
\hline \multirow[t]{2}{*}{ Extrato } & \multicolumn{3}{|c|}{ Postos médios } & \multirow{2}{*}{$\begin{array}{l}\text { Resultado do teste } \\
\text { estatistico (p-value) }\end{array}$} & \multirow[t]{2}{*}{ Conclusão } \\
\hline & II & IV & $\mathrm{V}$ & & \\
\hline Aquoso & 10.45 & 10.55 & 25,5 & $\mathrm{H}=19,35 \quad(\mathrm{p}<0,001)$ & $\mathrm{G} \mathrm{II}=\mathrm{G} \mathrm{IV}<\mathrm{GV}$ \\
\hline Etanólico & 13.45 & 17.05 & 16.0 & $H=0,88 \quad(p>0,05)$ & $G \mathrm{II}=\mathrm{GIV}=\mathrm{GV}$ \\
\hline
\end{tabular}

\section{DISCUSSÃO}

A atividade antimalárica da Momordica charantia foi avaliada ministrando, por via oral, à camundongos infectados com Plasmodium berghei, extrato aquoso ou etanólico, durante 5 dias consecutivos após a instalação da infecção, na dose de $1000 \mathrm{mg}$ de extrato por kg de peso corpóreo. A escolha do extrato aquoso baseou-se no fato que a maioria das plantas é utilizada pela população sob a forma de chás, preparados sempre em água, que extraem das mesmas, substâncias polares. Já o processamento com etanol poderia extrair substâncias pouco menos polares.

A dose de $1000 \mathrm{mg}$ por $\mathrm{kg}$ foi adotada como patamar máximo, já que esta concentração dificilmente seria atingida pela ingestão simples do chá.

Por outro lado, os testes de atividade antimalárica foram realizados apenas in vivo, visto que geralmente substâncias introduzidas no organismo são metabolizadas ou acopladas a outras existentes no mesmo, podendo com isso modificar sua atividade. Tal fato, explicaria porque algumas substâncias que mostram atividade in vitro, não as apresentam quando submetidas in vivo e vice-versa ${ }^{20}$.

A via oral foi escolhida visto sua praticidade e sua ampla utilização pela população, evitando a necessidade de maior assistência por pessoal especializado. 
Ueno HM, Doyama JT, Padovani CR, Salata E. Efeito de Momordica charantia L. em camundongos infectados por Plasmodium berghei. Revista da Sociedade Brasileira de Medicina Tropical 29:455-460, set-out, 1996.

$O$ intuito do presente trabalho foi verificar o possivel efeito terapêutico e não profilático dos extratos. Desta forma, os extratos foram ministrados aos animais, do $2^{\circ}$ ao $6^{\circ}$ dia de infecção, a fim de que pudéssemos avaliar possivel efeito terapêutico sôbre a infecção já instalada, ou seja, sôbre hemácias infectadas e sôbre merozoitas por elas liberados, consequentes da esquizogonia eritrocítica.

A atividade antimalárica dos extratos de $M$. charantia foi avaliada em função da parasitemia e da sobrevida dos animais inoculados com o $P$. berghe .

A ausência de atividade antimalárica por nós encontrada corrobora os resultados de outros pesquisadores ${ }^{3} 182324$, que se utilizaram de metodologia as mais variadas. Por outro lado, os resultados encontrados por Misra e $\operatorname{cols}^{20}$ que obtiveram $88 \%$ de inibição de parasitemia em Mastomy's natalensis, tratados com extratos etanólicos de $M$. dióica, indicam atividade antimalárica em planta da família Cucurbitaceae.

Acreditando ainda na existência de atividade antimalárica em $M$. charantia, que a leva a ser indicada pela população, no tratamento de infecçóes por plasmodios humanos, torna-se interessante avaliar tal atividade frente aos $P$. falciparum, $P$. vivaxe $P$. malariae e para tanto preconizamos a metodologia descrita por Sala-Neto e cols ${ }^{29}$.

\section{SUMMARY}

According to the World Health Organization malaria is one of the major public bealth problems in Brazil and all over developing countries, where $80 \%$ of the population use traditional medicine to solve their primary medical problems. Both treatment and control of this parasitosis bave become difficult, because of parasite strains that are resistant to conventional drugs, sucb as chloroquine. That makes the search for new antimalarial drugs not only important but urgent. We aimed therefore at evaluating the effects of Momordica charantia L. (Cucurbitaceae) in mice infected with Plasmodium berghei. We used aquose and etbanotic extracts in a dose of $1000 \mathrm{mg} / \mathrm{kg}$ of body weight, orally, for five consecutive days (i.e. from day 2 to day 6 postinfection). We then followed up the parasitaemia during the course of infection. Although the population use this plant as an antimalarial, in our experimental conditions, $\mathrm{M}$. charantia extracts bave not shown such activity.
Key-words: Antimalarial activity. Momordica. Plasmodium berghei.

\section{REFERÊNCIAS BIBLIOGRÁFICAS}

1. Abatan MO, Makind MJ. Screening Azadirachta indica e Pisum sativum for possible antimalarial activities. Journal of Ethnopharmacology 17:8594, 1974.

2. Amorim CZ, Flores CA, Gomes BE, Marques AD, Cordeiro RSB. Screening for antimalarial activity in the Genus Potomorphe. Journal of Ethnopharmacology 24:101-6, 1988.

3. Amorim CZ, Marques AD, Cordeiro RSB. Screening for antimalarial activity in the plants of the Cucurbitaceae family. Memórias do Instituto Oswaldo Cruz 86(Suppl II):177-80, 1991.

4. Basco LK, Le Bras J. In vitro acitivity of artemisinin derivates against African isolates and clones of Plasmodium falciparum. The American Journal of Tropical Medicine and Hygiene 49:3017,1993.

5. Bjorkman A, Phillips-Howard PA.Adverse reations to sulfa drugs: implications for malaria chemoterapy. Bulletin of World Health Organization 69:297-304, 1991.

6. Braz LMA, Amato Neto V, Campos R, Baillot AA, Foster R, Nascimento SAB. Estudo sobre a possivel atividade terapêutica da deferoxamina na infecção experimental de camundongos pelo Plasmodium bergbei. Revista do Hospital das Clínicas da Faculdade de Medicina de São Paulo 45:253-5, 1990.

7. Carvalho LH, Brandão MGL, Santos-Filho D, Lopes JLC, Krettli AU. Antimalarial activity of crude extracts from brazilian plants studied in vivo in Plasmodium berghei - infected mice and in vitro against Plasmodium falciparum in culture. Brazilian Journal of Medical and Biological Research 24:1113-1123, 1991.

8. Carvalho LH, Krettli AU. Antimalarial chemotherapy with natural products and chemically defined molecules. Memórias do Instituto Oswaldo Cruz 86:181-4, 1991.

9. Carvalho LH, Rocha EMM, Raslan DS, Oliveira AB, Krettli AU. In vitro activity of natural and synthetic naphthoquinones against erythrocytic stages of Plasmodium falciparum. Brazilian Journal of Medical and Biological Research 21:485-7,1988.

10. Ferraroni JJ, Speer CA, Hayes J, Suzuki M. Prevalence of chloroquine-resistante falciparum 
Ueno HM, Doyama JT, Padovani CR, Salata E. Efeito de Momordica charantia L. em camundongos infectados por Plasmodium berghei. Revista da Sociedade Brasileira de Medicina Tropical 29:455-460, set-out, 1996.

malaria in the Brazilian Amazon. The American Journal of Tropical Medicine and Hygiene 30:526. 30, 1981.

11. Fontes CCJ, Bathurst I, Krettli AU. Plasmodium vivax anti sporozoite antibodies in individual exposed to a single malaria outbreak in a non endemic area. American Journal of Tropical Medicine and Hygiene 44:28-33, 1981.

12. Freese JA, Rossouw EJ, Gouws SE, Sharp BL. In vitro sensitivity of southern African isolates of Plasmodium falciparum to halofantine. Annals of Tropical Medicine and Parasitology 87:235239, 1993.

13. Garavelli PL, Corti E. Chloroquine resistance in Plasmodium vivax. The first case in Brazil. Transactions of the Royal Society of Tropical Medicine and Hygiene 86:128, 1992.

14. Gingras BA, Jensen JB. Antimalarial activity of azithromycin and erythromycin against Plasmodium bergbei. American Journal of Tropical Medicine and Hygiene 49:101-105, 1993.

15. Janse CJ, Waters AP, Kos J, Lugt CB. Comparison of in vivo and in vitro antimalarial activity of artemisin, dihydroartemisinin and sodium artesunate in the Plasmodium berghei - Rodent model. International Journal of Parasitology 24:589-594, 1994.

16. Jiang JB, Li CQ, Guo XB, Kong YC, Arnould K. Antimalarial activity of mefloquine and ginghaosu. Apud: Chawira AN, Warhurst DC, Robison BL and Peters, 1987 - The effects of combinations of ginghaosu (Arthemisin) with standard antimalarial drugs in the supressive treatment of malaria in mice. Transactions of the Royal Society of Tropical Medicine and Hygiene 81: 554-558, 1982.

17. Kingman S. Malaria runs riot on Brazil's wild frontier - the rapid loss of the rainforest is not the only problem facing the Amazon basin. Brasil is also suffering from a massive epidemic of malaria. New Science 123:24-33, 1989.

18. Lins-Brandão M G, Botelho MG, Krettli U. 1985 Quimioterapia experimental antimalárica com produtos naturais. I- Uma abordagem mais racional? Ciências e Cultura (São Paulo) 37:115263, 1985.

19. Marques AC. Human migration and spread of malaria in Brazil. Parasitology Today 3:166-170, 1987.

20. Misra P, Pal NL, Guru PY, Katiyar JC, Tandon JS. Antimalarial activity of Traditional Plants against
Erythrocytic stages of Plasmodium berghei. International Journal of Pharmacognosy 29:1923, 1991.

21. Myint PT, Shwe T. Controlled clinical trial of artmether (ginghaosu derivate) versus quinine in complicated and severe falciparum malaria. Transactions of the Royal Society of Tropical Medicine and Hygiene 81:559-61, 1987.

22. Myint PT, Shwe T, Soe L, Htut Y, Myint W. Clinical study of the treatment of cerebral malaria with artemether (ginghaosu derivate). Transactions of the Royal Society of Tropical Medicine and Hygiene 83:72, 1989

23. Neves EB, Padovani CR, Salata E. Uso de fedegoso e melão de São Caetano como antimaláricos. In: Anais da IX Jornada Paulista de Parasitologia, 12 e 13/06/92 - Ribeirão Preto-SP.,pg. 29. 1992.

24. Ornelas HM, Di Stasi LC, Curi PR, Salata E. Efeito de plantas medicinais sobre a infecção pelo Plasmodium berghei em camundongos. Revista de Ciências Farmacêuticas, São Paulo 12:71-80, 1990.

25. Phillipson JD, O'Neill MJ. Antimalarial and amoebicidal natural products. In: Hostettmann $\mathrm{K}$, Lea PJ. Biologically active natural products. Clarendon Press, Oxford, cap.4, p.49-64, 1987.

26. Phillipson JD, O'Neill MJ. New leads to the treatment of protozoal infections based on natural product molecules. Acta Pharmaceutica Nordica 1: 131-43, 1989.

27. Rang HP, Dale MM. Drogas antiprotozoários. In: Farmacologia, $2^{a}$ edição, Guanabara Koogan. Rio de Janeiro, cap. 37, p.520-30, 1993

28. Sala-Neto F, Nascimento NP, Urdaneta M, Tosta CE. Multirresistência do Plasmodium falciparum às drogas antimaláricas: ocorrência e relação com marcadores bioquímicos. Revista da Sociedade Brasileira de Medicina Tropical 25(supl. II):53-4, 1992.

29. Sala-Neto F, Silva JS, Pires RO, Nascimento NP, Brenner C, Borebli JP, Tosta CE. Uma nova metodologia para a avaliação da atividade antimalárica de produtos vegetais: aplicação ao estudo de 83 espécimes da flora brasileira. Revista da Sociedade Brasileira de Medicina Tropical 25(supl. II):92, 1992.

30. Santos MAV, Couto AA, Oliveira SG, Rosario VE. Estudos in vitro dos níveis de resistência do Plasmodium falciparum a drogas, de 1983 a 1986. Revista do Instituto de Medicina Tropical de São Paulo 29:346-53, 1987. 